\title{
Simulation-Based Continuing Education in Health Care Social Work: A Case Study of Clinical Training Innovation
}

\author{
Emma D. Sollars ${ }^{1}$ (D) Nancy Xenakis ${ }^{1}$ \\ Accepted: 1 April 2021 / Published online: 3 May 2021 \\ (c) The Author(s), under exclusive licence to Springer Science+Business Media, LLC, part of Springer Nature 2021
}

\begin{abstract}
Health care social workers practice in a fast-paced, demanding work environment, and do not always have the opportunity to reflect meaningfully on their work or to practice new skills. This article describes an innovative program, the Partnership for Excellence in Social Work Practice in Health Care ("the Partnership"), which provides a professional development opportunity for health care social workers and contributes to the larger mission of providing comprehensive and coordinated care to high-risk populations. The Partnership aims to help social workers respond to the current challenges of health care practice through simulation learning as an educational reflective practice technique. Through this program, social workers at all levels of experience have the opportunity to practice real-world scenarios in a safe and structured space, receive feedback, and reflect on their skills. The Partnership utilizes professional actors who portray patients, doctors, and care partners (formal or informal caregivers) in case examples that explore key issues in the field. This enables learners to be exposed to a representative set of patient experiences, expediting the development of their skills, enhancing their competence, and facilitating the habit of ongoing reflection in practice and in the development of one's professional identity. Implications of the program for clinical social work practice and directions for future study are discussed.
\end{abstract}

Keywords Case development $\cdot$ Healthcare $\cdot$ Reflective practice $\cdot$ Social work education $\cdot$ Simulation $\cdot$ Standardized patient

\section{Introduction}

The American Academy of Social Work and Social Welfare launched "The Grand Challenges for Social Work," an initiative to focus the profession's contribution to fostering social progress. One of the 12 named challenges, Close the Health Gap, enlists social workers to lead the way in helping health care professionals and others to understand the complex pathways connecting social and economic disadvantage to health risks and poor health outcomes (Close the Health Gap. GC Fact Sheet No. 2, 2018). Health risks and poor health outcomes are correlated with structural and sociodemographic disadvantages (e.g., poverty, low education levels, substandard housing, and limited access to services), and such disadvantages are also linked to high rates of cooccurring chronic medical conditions (e.g., diabetes, hypertension, and cardio vascular disease) (Dunker \& Benjamin,

Emma D. Sollars

emma.sollars@mountsinai.org

1 Department of Social Work Services, The Mount Sinai Hospital, New York, NY, USA
2020; Sandro, 2018; Walters et al., 2016). Also, exposure to trauma and violence (e.g., intrapersonal, intergenerational, structural levels of trauma) are associated with co-occurring psychopathology (e.g., post-traumatic stress disorder and depression) (Matthews \& Phillips, 2010). Addressing these associations requires multiple levels of intervention, a hallmark of social work practice (Stanhope et al., 2015).

Existing health care systems are actively searching for comprehensive care solutions that focus on prevention, well-being, and collaborative care. It is important that social workers actively contribute to this effort, yet a two-year graduate education simply does not allow for the depth of skills training that is required (Brown et al., 2017). Continuing Education Units (CEUs) are now required in the U.S. for social work licensure renewal, designed to promote professional development post-MSW, but there are limitations and exceptions that keep this system from delivering optimal results. Meanwhile, health care social workers practice in a fast-paced, demanding work environment with complex cases, a situation not conducive to reflecting meaningfully on their work or to acquiring new skills. 
This paper presents and discusses a unique continuing education program that gives health care social workers opportunities to reflect on their work and gain new skills in a safe and non-judgmental setting. It provides a review of the literature on simulation learning, and explains the origins of the program's learning theories and methodology; it also examines their application to social work and how the program was conceptualized, funded, developed, and implemented. A distinctive feature of the program is that it uses simulation involving actors to enhance clinical practice skills for professional social workers in a health care environment. Elements of a patient case and excerpts from actual cases are described. Then, initial results and implications for clinical social work practice are shared. Finally, the future direction of the program is discussed, including its scalability to include other health settings and disciplines.

\section{Literature Review}

The use of Human Based Simulation Learning (HBSL)—or guided, interactive, and reflective learning in health care, with actors portraying patients-began in 1964 (Barrows \& Abrahamson, 1964), and is now widely used as part of medical schools' curricula in the U.S. and Canada (Jones et al., 2015). There is evidence that it is an effective learning tool in medicine (Gardner et al., 2008; Lasater, 2007; Reilly \& Spratt 2007). Training of health care providers may also include "high-fidelity" simulations that offer technical and procedural practice with mannequins and other equipment that simulate clinical situations (Kim et al., 2016); however, the focus of this paper is HBSL.

HBSL aims to imitate reality while offering a skills-based clinical experience in a safe and secure environment (Cant $\&$ Cooper, 2010; Fowler-Durham \& Alden, 2007). Hovancsek describes the aim of simulation as: "to replicate some or nearly all of the essential aspects of a clinical situation so that the situation may be more readily understood and managed when it occurs for real in clinical practice" (Hovancsek, 2007, p. 3). A key aspect of simulation education is the ability to repeat practice to consolidate learning and develop competence (Hogg et al., 2006; Issenberg et al., 2005; Kardong-Edgren et al., 2008).

HBSL has been widely studied as a teaching methodology with medical students and there is a vast body of literature on the topic. Recent meta-analyses highlight its effectiveness with medical students in the areas of critical care medicine (Beal et al., 2017) and delivery of bad news (Johnson \& Panagioti, 2017). Simulation has also been extensively studied in nursing education, with a recent meta-analysis demonstrating effectiveness with a range of learning objectives (Kim et al., 2016). HBSL has accordingly been endorsed by nursing professional bodies
(National Council of State Boards of Nursing, 2005) and educators (Anderson, 2007; Haluck et al., 2007; Hammond, 2004; Hanberg, 2008; Henneman \& Cunningham, 2005; McLaughlin et al., 2008). A recent analysis of several studies concluded that simulation is an effective training tool to improve the skills of professional registered nurses (Hegland et al., 2017).

In the realm of continuing education, HBSL has been used as a tool to train health care professionals, including doctors, in a wide range of clinical skills and tasks from surgical procedures (Dunkin et al., 2007; Kneebone et al., 2002; Nackman et al., 2003; Sturm et al., 2008) to patient communication (Murray et al., 2008; Kneebone et al., 2006). A 2012 survey of continuing education programs for professionals in health care describes the existence of simulationbased continuing education programs in a range of health professions including medicine, nursing, pharmacy, and others; however, social work was not included (Rosen et al., 2012). A 2019 survey of simulation-based continuing education experiences in health care identified usage with physicians and medical students, physician assistants, nurses, emergency medical technicians (EMTs), pharmacists, and members of allied health professions such as physical therapy; social work-focused simulations were not discussed, nor were social workers identified as part of interprofessional teams utilizing HBSL (Gavilanes and An, 2019).

These oversights notwithstanding, HBSL has been used successfully in graduate social work programs, with growing literature on the topic in recent years (Bogo et al., 2014; Craig et al., 2017; Logie et al., 2013). A recent scoping review cites evidence for its efficacy as a teaching and learning tool in key domains of social work education; there is also significant literature in support of the idea that HBSL facilitates ethical training opportunities, in which clients themselves are not harmed by learner mistakes (Kourgiantakis et al., 2020). In particular, HBSL is an efficacious teaching method in health care as a subspecialty of social work education in that it affords students an opportunity to practice their clinical skills in a realistic context but reduces the risk of doing so with real patients who may be negatively impacted by student mistakes or inexperience (Craig et al., 2017; Kourgiantakis et al., 2020).

There is a gap in the literature on the use and efficacy of HBSL as a tool in the continuing education of professional social workers. As cited above, HBSL has been used effectively within work settings of several other health care disciplines. According to the data synthesized in a 2020 scoping review, only eight percent of studies on social work and simulation included professional social workers (Kourgiantakis et al., 2020). The same scoping review indicated that no literature exists focused specifically on HBSL as a continuing education offering for experienced social work practitioners (Kourgiantakis et al., 2020). A distinctive 
feature of the program discussed in this paper is its focus on skill development for professional health care social workers, rather than students.

\section{Training Model}

\section{Conceptual/Theoretical Framework}

The program discussed in this paper, known as the Partnership for Excellence in Social Work Practice in Healthcare (the "Partnership"), draws on two widely used learning theories for its theoretical base-Experiential Learning Theory (Kolb, 1984) and Andragogy (Knowles, 1978)_-and uses HBSL as its methodology.

The Partnership mirrors the four basic stages identified by Experiential Learning Theory: concrete learning, reflective observation, abstract conceptualization, and active experimentation. As this theory's name denotes, it emphasizes the critical role that experience plays in the learning process and postulates that "learning is best conceived as a process, not in terms of behavioral outcomes" (Kolb, 1984, p. 26). As such, learners can enter the cycle at any stage and effective knowledge and skill acquisition occurs as learners progress through its logical sequence over any period of time (Kolb \& Kolb, 2013).The Partnership applies HBSL in each of these stages, as actors dramatize case studies in which learners actively participate. Particular emphasis is placed on reflective observation in the session with social work peers, facilitators, and the actors. Active experimentation with clinical practice techniques both in session and in practice settings is encouraged.

Widely recognized as shaping adult education, Knowles' (1978) theory and practice of Andragogy focuses on the unique needs of adult learners. Knowles identified four principles of adult learning, which the Partnership incorporates in its program design. Specifically, the Partnership's adult learners are involved both in the planning and evaluation of their instruction through contribution of cases to develop the curriculum, and through their feedback, which informs continuous program improvement. Learners participate in a safe setting that encourages mistakes as part of the learning process. The entire HBSL experience complements this "safe space" concept, since it encourages trial and error, with a focus on the complexities of a case and exploring different approaches to serve patient needs.

A critical aspect of simulation is constant feedback (Jones et al., 2015). This is mainly provided through debriefing, which is a unique opportunity to reinforce the core assumptions of adult learning, as well as to provide external motivation and stimulate guided reflection. Understanding how an experience encountered in simulation affects future practice is a crucial step to improve performance (Kaufman, 2003).
Simulation alone does not guarantee learning, but within the proper environment, it is a tool of critical importance for curricula oriented by adult learning theory (Gaba, 2004). Reflection, in fact, can be described as the overarching conceptual frame for HBSL in any discipline. The work of Schön (1983), who was particularly interested in the process of adaptation to change in a professional context, is seminal to an understanding of reflective practice. Linda Bruce expanded on Schon's work as it applies to the social work professional (Bruce, 2013). Several key points in Bruce's work provide the framework for the Partnership.

Bruce defines reflective practice for social workers as ongoing, deliberate reflection, the mechanism by which professionals develop enhanced competence (Bruce, 2013). The idea that reflective practice is necessary for social workers is thus consonant with the National Association of Social Workers (NASW) value of competence in professional practice (National Association of Social Workers, 2017). Maturation of one's professional self-concept as a social worker, Bruce argues, requires the habit of ongoing reflective practice and critical self-awareness. Bruce also proposes that for social workers, there is often a gap between what she calls "tacit knowledge" - that is, the art of clinical practice, one's "repertoire" or toolbox as a practitioner-and one's ability to describe this knowledge in clinically appropriate terms. One risk of not addressing this gap is that the social worker, unable to account for their actions in a persuasive way, will be viewed as having less professional credibility (Bruce, 2013).

There is particular resonance to Bruce's ideas in a health care setting. Health care social workers often play a critical role on interprofessional teams, where maintaining professional credibility is essential to provision of effective patient advocacy and service. This gap between what you do and how you describe your work can be keenly observed, particularly in early-career social workers. The Partnership's use of HBSL as an educational reflective practice methodology for adult learning, specifically for social workers with various levels of practice experience in the hospital setting, helps them respond to rapid and complex situations they encounter on a regular basis with increased comfort, confidence, and applied knowledge. This ability to present their perspective clearly using clinically appropriate terminology demonstrates their expertise to other interprofessional team members.

\section{Program Overview}

The Department of Social Work Services within the hospital ("the Department") received funding for a three-year initiative to develop the Partnership from the hospital's auxiliary board. The Partnership collaborated with the simulation center within the hospital's medical school to adapt 
existing simulation learning methods for medical students to a method for social workers to engage in reflective practice, primarily through the use of actors portraying standardized patients (SP), doctors (SD), or care partners (SC) (care partners may be formal or informal caregivers).

The Partnership's actors portraying SPs are trained to simulate the psychosocial situations, feelings, and reactions of patients with serious acute and chronic medical and behavioral health conditions, illnesses that are often compounded by sociodemographic disadvantage. SDs are trained to simulate the concerns of physicians collaborating with social workers in a health care setting. SCs are trained to simulate the psychosocial experience of patients' care partners. This program does not require the SD to obtain any medical expertise; rather, since the purpose of the doctor in the simulated scenario is to simulate the experience of interprofessional collaboration for the social work learner, the $\mathrm{SD}$ is required to learn to recognize competencies in the social work learner pertaining to communication skills, collaboration, and projection of professionalism, not medical knowledge. For example, in the case scenario discussed below, the actor, in character as the SD, may give the social work learner feedback on whether they experienced the social work learner's mediation attempt between doctor and patient as collaborative, and why the approach was or was not effective. These SPs, SDs, or SCs work with two seasoned and trained social worker facilitators in small group sessions, with the social work learners taking turns engaging the patient. The group of facilitators meets regularly as a work group (the "Workgroup") to develop and refine case materials, share best teaching practices and challenges, and evaluate program outcomes. There is also an Advisory Group, comprised of departmental leaders experienced with HBSL, to develop program strategy, including future funding and sustainability opportunities.

The SPs, SDs, or SCs participate in the provision of feedback about the learners' performance. The simulation sessions utilize a "Time-in, Time-Out," or "TITO," methodology (Barrows, 1993; Cantrell et al., 1997; Gligorov et al., 2015). The TITO method allows for the simulation to be paused with a time-out, initiated by either the facilitator or the learner, to provide the opportunity to reflect on the dynamics of the interaction. After this reflection, a time-in restarts the simulation, either where the session was paused or to a previous point in time. The same learner may continue, or a different learner may take over and continue the improvisation. In the time-outs, the SP/SD/SC can also be used as a source of learning and can be consulted (in character) about why a learner's intervention was effective or not effective. This facilitation style fosters experiential learning. Learners reflect and receive feedback in real time (Barrows, 1993; Cantrell et al., 1997; Gligorov et al., 2015).
HBSL approaches have a range of applications in health care; these may focus on assessment and/or the development of high-risk skills, or on professional development and exploration (Rosen et al., 2012). The SPs identified for the Partnership had extensive prior experience in human simulation exercises with medical students, which are often evaluative with students being graded on their performance in SP exercises. For medical student encounters, the SPs are typically trained to simulate medical illness, and to respond in the simulation scenario to concrete, readily observable actions by the medical student, such as the student making eye contact, or asking the SP how they would like to be addressed.

In developing a program for professional social workers, three characteristics emerged, with implications for design of case scenarios. First, the goal of the program was to support professional development and to enhance the competence of professional social workers; there was no evaluative component, and articulating this to both the SPs and the learners became an important criterion for establishing a productive learning environment. Second, the competencies identified for enhancement tended to be more abstract than those identified for medical students. Social work competencies as identified in this program focused less on the articulation of specific phrases or demonstration of specific actions, and more on clinical judgment, self-awareness, and psychosocial assessment. Last, the Partnership focused on professional social workers, many of whom had been in practice for many years, in contrast to inexperienced medical students operating in an academic environment. Understanding all the above characteristics helped frame the case development process.

\section{Case Scenarios}

Because much of the existing literature about simulation focuses on either social work students or professionals in other disciplines, there was no specific template or framework to utilize when developing case scenarios. Several sources were considered, including existing case materials for medical students, social work practice textbooks, literature about simulation in social work education, and the practice experiences of staff involved in the case development process. It was critical to ensure that cases developed were reflective of real social work practice in health care, and met the actual learning needs of staff. Case development occurred through use of in-depth interviews with staff from a range of practice areas and with varying levels of experience, and inviting all Department social work staff to contribute case materials they considered foundational, transformative, complex, and/or inspirational in their careers. The Department's call for cases generated enthusiastic participation from social workers; brief vignettes, de-identified and 
coded for dominant themes, were developed. Many of the challenges identified by staff were common across the professional spectrum. Several key themes emerged from this exercise. The most frequently cited themes were the challenge of working with a so-called "difficult" patient, managing clinical boundaries effectively, and the challenges of interprofessional collaboration.

The Workgroup next turned its attention to determining what the elements of a case would include. Those used by the hospital's simulation center for training medical students, and by Factor-Inwentash Faculty of Social Work at the University of Toronto to train graduate students interested in health care, were examined (Bogo et al., 2014; Craig, 2016; Craig et al., 2017). The Workgroup developed a framework, which included premises, learning objectives, and competencies. Premises are agreed-upon assumptions about social work practice in health care; the goal of articulating these is to ensure that all participants in the teaching-learning exchange are aligned on the learning target. Next, the Workgroup developed learning objectives, which flow from the rationale(s) determined by the premises. The Workgroup developed both general learning objectives, which apply to every simulation learning case, and case-specific objectives. Both guide the development of the challenges embedded in the case material (Bruce, 2013; Schön 1983). Finally, the Workgroup identified competencies to support the stated learning objectives. The Workgroup identified both general social work competencies that are foundational to any direct practice encounter, and also case-specific competencies which are the components of effective clinical practice in the given case scenario. Ideally, learners are using most or all of these general and specific competencies, both in the simulation and in real practice encounters. The Partnership aims to help social workers identify and name these competencies, thus addressing the gap Bruce (2013) identified between what social workers know how to do (e.g. be empathetic) and their ability to articulate how they know they are doing it (e.g. using active listening, tuning in to the patient, providing both simple and complex reflections).

With the framework articulated, the elements of a full case were developed and included in a comprehensive program user guide. The case elements are: Prerequisite Readings; Premises; Learning Objectives; Competencies; Detailed Patient Description and Case Overview; Abbreviated Case Description for Learners; Ideal "Script" - Guidelines for Dialogue; Post-Simulation Handout; and Feedback Survey. The "ideal script" is the actual dialogue that the social work learner and SP/SD/SC might use in the scenario. Of course, it is impossible to script a simulation experience, as it is by nature improvisational and every learner brings something new to the case scenario. However, it can be useful to the SP/SD/SC to prepare by reviewing a scripted dialogue indicating how the scenario might unfold. Table 1 shows how some of these elements interrelate in the case, "I Felt Disrespected-Interdisciplinary Communication Challenges" (wording lightly edited from the original for clarity).

With the framework established for each case, the Workgroup focused on developing detailed narrative patient descriptions, which helped conceptualize the issues in the case and the patient "character." In the case example in Table One, the detailed patient description included both an extensive backstory for "Tick," the SP, and for "Dr. Smith," the SD. The narratives also enabled the Partnership collaborators at the medical school's simulation learning center to cast and train the actors for each case.

To create an actual script for each of the cases, the Workgroup adapted a framework developed by colleagues at the Factor-Inwentash Faculty of Social Work at the University of Toronto (Craig, 2016), in which an "ideal script" is generated. The ideal script is not a rigid document, but rather a skeleton on which the SPs/SDs/SCs can improvise and build. Suggested dialogue is anchored by the key social work competencies that frame the case. Key tasks for the learners, the SPs/SDs and SCs, as well as the facilitators, are all identified in each phase of the case: the Joining, Working, and Ending Phases (Craig, 2016).

The Workgroup experimented with different approaches to scripting the encounters. In the first case developed, the Workgroup generated a detailed script, with a lot of suggested dialogue and specific verbal cues to which the SP was to respond. In implementing this approach, it became clear that this much detail was too constraining to enable learners to meet the objectives outlined for the sessions. The learning objectives encompass some concrete skills but also skills known as "meta-competencies," in particular, "conceptualization of practice, intentional use of self/self-regulation, and learning and growth as a professional" (Bogo et al., 2013, p. 262). By applying this framework to the scripting process, it became clear that the script needed to be sufficiently elastic so as to enable learners to both utilize and reflect upon these dynamic skills, which incorporate verbal cues but also nonverbal communication, thought processes, and expressions of emotion.

The SPs/SDs/SCs also felt constrained by the initial scripting effort, as often learners would say something different than what had been scripted, generating authentic feeling from the SP/SD/SC that may not match the precise lines. One of the benefits of HBSL is that the SP/SD/SC is a real person, able to respond authentically and improvise based on the learner's approach in the session, yet the SPs/ SDs/SCs felt hampered by the script from manifesting this authentic response. For example, in one case scenario, the first task for the social work learner was to establish mutual understanding of the patient's concern. In the original script, the completion of this task was tied to the learner verbalizing this understanding in a concrete way, such as "I would feel 
Table 1 Case scenario framework

Abbreviated case description for learners
Premises

Learning objectives

Competencies
Theresa Jones is a 20-year-old woman who was brought into the Emergency Department (ED) after passing out in the street. According to the chart, she lives in Queens, NY. Her emergency contact is her grandmother. Her care is covered by a managed Medicaid plan. The patient is seemingly non-adherent with her diabetes regimen, resulting in a hypoglycemic emergency that caused her to pass out.

Now, she is at her first post-discharge clinic appointment. The physician, Dr. Smith, was discussing medical adherence when the patient became agitated and confrontational. The situation escalated and the patient has demanded to see a different doctor. The patient, in prior encounters with the Health System, has already cycled through multiple providers.

You, the social worker, were called to intervene. Dr. Smith told you that patient is "difficult" and reports that, during her recent ED visit, she was confrontational and one of the nurses thought the patient was trying to hit her. Dr. Smith didn't give you much information, but appeared frustrated and asked you to go in and "deal with her." You met with the patient in an outpatient treatment room.

In the course of your assessment with Theresa, you successfully de-escalated the situation. You learned that Theresa likes to be called "Tick." You learned that she lives with her grandmother, who has multiple diabetic complications and is very seriously ill and declining rapidly. Tick is the sole caregiver and has no other supports. Tick appeared quite knowledgeable about her own diabetes and reported that she tries her best but doesn't have a lot of support or resources to draw on to help her. She expressed anger at being labeled "noncompliant" and feels like Dr. Smith made assumptions about her and talked down to her, which she experienced as disrespectful. She retaliated and called him an "asshole." Your impression of Tick is that she actually really needs and wants help, but doesn't know how to ask for what she needs and gets frustrated and angry quickly. Behind the anger, you suspect she is quite scared of what will happen to her.

At the end of your meeting with Tick, she agreed to meet again with the doctor with you, the social worker, present. She was still guarded, but cautiously optimistic that perhaps you could do something to help the situation. You are now going to go find Dr. Smith in the clinic, and attempt to facilitate a family meeting with Tick. When you locate Dr. Smith, he is striding down the clinic hallway, seemingly on his way somewhere. Dr. Smith is the new clinic director. You've been working with him about three months. You have a cordial relationship but don't know him that well and haven't worked directly with him very much as of yet. You know he is a highly regarded physician with expertise in diabetes, and he has a reputation for excellent patient care.

Your goal in this scenario is to engage Dr. Smith in a productive discussion about Tick, paving the way for a family meeting.

1. Social workers liaise between patients and providers throughout the health care system.

2. Social workers add value to the interdisciplinary care team via use of comprehensive biopsychosocial assessments and a holistic, person-in-environment lens.

3. Social workers, like all care team members, bring their own feelings/thoughts about power, authority, and culture into their interdisciplinary interactions.

4. Social Workers communicate in both formal and informal ways with interdisciplinary care team members, and both may require professional skills.

5. A hallmark of effective interdisciplinary collaboration is when all members of the care team are acting in the patient's best interest, within the scope of their role/responsibility on the interdisciplinary care team.

1. Effectively articulate the patient's perspective while preserving patient confidentiality.

2. Advocate for the patient, being mindful of her right to self-determination.

3. Adjust communication technique/style with colleagues and patients in a professionally appropriate way, as indicated in the situation.

4. Gain trust and confidence of the medical provider and partner with provider to meet patient needs.

5. Contract with the patient and provider for the next step in work/care/treatment.

6. Reflect on the dynamics of the situation as they pertain to power, authority, and culture, and how the dynamics may present challenges/ opportunities, or trigger feelings, for the social worker.

7. Attend to the power disparities in the interaction in a way that is consistent with the social work core values of service, social justice, dignity and worth of the person, importance of human relationships, integrity, and competence.

1. Use active listening, reflective statements, and empathic responses.

2. Use concise, goal-oriented language in communication.

3. Use language that is inclusive of all disciplines' perspectives and range of expertise.

4. Utilize person-in-environment lens (e.g. explanation of patient behavior as a result of uncovered stressors, psychoeducation regarding medical diagnosis and mental health correlation, etc.).

5. Contract with patient and provider to develop a patient-centered action plan.

6. Model appropriate professional boundaries throughout the encounter.

7. Model appropriate language and communication skills, as indicated by the situation.

8. Use reflective practice to become aware of the dynamics of the situation and how they may inform the encounter(s).

9. Identify strengths where possible to do so and capitalize on these to help inform the encounter.

10. Communicate so the patient and provider feel respected and understood.

11. Demonstrate worker self-awareness about encounter and discuss strengths and challenges in the process.

12. Acknowledge when to seek help/supervision. 
the same way if that happened to me." In practice, it became evident that "mutual understanding" could be expressed in many ways, both verbal and non-verbal. Learners might say something less specific, like "I respect you, and I hear how difficult this must be," or even just sit in silence with the patient's feelings, and these approaches were often effective in impacting the SP and making her feel heard and understood. The SPs' input about what felt meaningful was critical to the process, and showed that it was appropriate to broaden the range of interventions considered effective to complete the specified task. Authenticity mattered more than the specific words or the order in which they were spoken. Ideally, this is a balance, as is the balance between thinking and feeling as a practitioner, or between the skill and the art of clinical practice. The Workgroup and Partnership collaborators at the medical school's simulation center worked with the $\mathrm{SPs} / \mathrm{SD}$ /SCs to develop a sophisticated understanding of the social work competencies, enhancing the SP/SD/SCs' ability to improvise, challenge learners appropriately, and remain flexible throughout the session.

In subsequent scripting efforts the Workgroup wrote suggested dialogue which was then provided to SP/SD/SC with detailed character descriptions; however, the SP/SD/SC was encouraged to improvise and create his own language to express the ideas embedded in the case materials. The cues for which the SP/SD/SC listens in order to move the case forward are not only verbal, but encompass non-verbal behavior and feelings, and a genuine expression of empathy on the part of the learner. As the SPs/SDs/SCs participate in sessions repeatedly over time, they come to know and inhabit characters. Material comes out in the improvisation that was never considered in the original scripting process, but that often produces effective learning moments. The exchange between the SP/SD/SC, learner, and facilitator is a dynamic and collaborative effort.

\section{Program Implementation}

Establishing a safe space for learning was a key element in program implementation. In this context, a safe space implies an environment in which learners are comfortable participating, empowered to take risks, and encouraged to be vulnerable in front of colleagues; it also implies an establishment of confidentiality and mutual support in which learning can take place. In each session, facilitators begin by inviting the learners to introduce themselves, their program or service area within the hospital, and their gender pronouns. Then the facilitators ask each participant to share any feelings they may be having at the outset of the session, and the facilitators reflect on their own feelings as well. Learners typically disclose a mixture of anxiety and excitement, as well as feelings of pressure or distraction, knowing they must return to a busy unit or clinic after the session. To mitigate this, supervisors in the Department are asked to provide coverage for learners while they are in a session, so that both disruption and distraction can be minimized. Facilitators also use the introduction to discuss ground rules, including confidentiality; review how the session will run and the TITO method; and encourage exploration and risk-taking. Facilitators also discuss the benefits of reflective practice in a consequence-free environment, and the potential benefit of transferring learning into real practice once the session is concluded.

The cases, grounded in real practice experience, offer enough elasticity and complexity to accommodate the learning needs of both early career (less than three years of post-master's experience) and experienced practitioners. Experienced learners often have a more sophisticated clinical awareness and language to describe their actions in sessions. However, the act of intentionally reflecting on one's practice, at any stage of one's career, is beneficial (Bruce, 2013). Participation by all social workers at all levels of practice is strongly encouraged. Social workers are autoenrolled into sessions on a rotating basis to ensure a mix of participants; staff may also volunteer to attend sessions of their choosing if more convenient. Continuing education credits are offered for each session.

\section{Discussion and Implications for Clinical Social Work Practice}

This article addresses a glaring gap in the literature with regard to continuing education for social work practitioners at all levels. It examines the Partnership's focus on reflective practice through use of HBSL, based on real-world health care cases in a safe setting, for professional development of social workers in health care. Further research is needed to weigh HBSL against other approaches for the continuing education of social workers.

Clinical educators working with social work professionals should be aware of the importance of including social workers in program development and curriculum building. Feedback from the Partnership's Advisory and Facilitator Work Groups supports this approach, as does one of its foundational learning theories, Andragogy (Knowles, 1978). Such a collaborative process helps ensure that continuing education material is representative of actual practice experience, fosters social workers' professional growth, and gains their endorsement and active participation.

The program aims to enhance the skill and professionalism of social workers in a health care environment, in service of the ultimate goal of providing improved patient care, and to better understand the ways in which professional training utilizing HBSL impacts patient outcomes. Many 
factors contribute to effective patient care and it is difficult to measure. Formal analysis of the program is required as the Partnership grows.

Over the initial five years of the program, 130 sessions were conducted with 807 total learners (433 unique). Although program outputs (number of facilitators trained, number of sessions conducted, and number of learners) are measured, along with short-term outcomes (learner and facilitator satisfaction with program, post-session selfreporting of case-specific competencies), the goal is to measure mid-term outcomes, such as level of application of the competencies in one's actual practice setting at various time intervals ( 3 and 6 months), and eventually to evaluate long-term measures, such as patient, care team, and partner satisfaction, and patient health outcomes. The Partnership's program evaluation tool will continue to evolve, tapping on existing program evaluation tools and the expertise of the data analytics team at the medical school. Edits to the social worker annual performance evaluation at the hospital, so that it can target the competencies featured in the Partnership's cases, will be explored. Finally, patient satisfaction data and other institutional reports can be examined for evidence of any correlation between participation in the Partnership and selected outcome measures.

This case study, in developing and implementing a HBSL program for professional health care social workers, has numerous implications for clinical social practice, both within the program's home institution and in the field of health social work. The program itself will continue to evolve by expanding its case library; a planned future case focuses on post-acute care planning, a fundamental part of an inpatient's care experience and one where social work plays a central role. Given the COVID-19 global pandemic, transitioning existing cases to reflect current virtual and socially distanced social work practice, including donning and doffing personal protective equipment, will be explored, and Partnership sessions are already being offered via a virtual platform.

The Partnership Advisory Group is collaborating with the health system's development staff to explore foundation funding as well as funding from other sources. Given the current COVID-19 global pandemic and the increased national focus on systemic racism and health disparities, requests for funding highlighting the Partnership as one possible means to improve care for patients disproportionately affected by health risks and poor health outcomes are being pursued. This Group will also explore opportunities for the program to generate revenue through creation of video(s) to supplement the existing, copyrighted program user guide, and working with the institution's innovation team to launch it. Such a launch would include registering a new copyright and packaging, marketing, and selling the product to hospital social work departments locally and nationally. Thus scaled, the Partnership can be used to meet staff professional development requirements (including offering of CEUs to staff for licensure renewal), and continuous quality improvement (CQI) projects required of most hospital departments. A caveat of this replicability is the program's integrity and quality as it moves away from its primary sources of knowledge and expertise. However, this pitfall exists when scaling many products and services, and quality measures will be added to assist with retaining program integrity to the degree possible.

The option of having the Partnership's designers serve as consultants, and/or for them to directly provide the program to social workers in health care settings and social work students in health care field placements, has also been discussed. This possibility offers both a means of generating funding and the opportunity to scale the program so other external stakeholders can benefit. Initial efforts led by Social Work, Medicine, Spiritual Care, and Nursing to develop a curriculum for Interprofessional Education and Practice in health care have begun and leverage the Partnership's work in HBSL.

The program's emphasis on clinical development through experimentation and reflection reinforces the value of experiential learning as a mechanism for professional development (Kolb \& Kolb, 2013). Though formal program evaluation has yet to be undertaken, initial feedback about this program suggests that use of HBSL as a continuing education tool for professional health social workers enhances development of "meta-competence" (Bogo et al., 2013). Through deliberate reflection, social workers may be better able to make manifest their "tacit knowledge" and utilize their skills with increased intention (Bruce, 2013). This is a development that will have farreaching positive consequences for the quality of patient care in any setting where social workers are given the opportunity to avail of the program.

Social workers in health care are embedded in interprofessional teams and typically work at a rapid pace with complex cases. Engaging in reflective practice through this experiential technique may yield a greater sense of confidence and competence in their work, and contribute to the development and/or affirmation of their professional identity. It is currently unknown whether this enhancement is more relevant for early-career or experienced social workers; understanding the impact of this continuing education method throughout the span of a health social worker's career is a possible direction for future study.

Acknowledgements The authors would like to thank the Mount Sinai Auxiliary Board for its generous support of this project; the Partnership Advisory Group; the Partnership Workgroup; and the Morchand Center for Clinical Competence at the Icahn School of Medicine at Mount Sinai. 
Funding The Mount Sinai Hospital Auxiliary Board.

\section{Declarations}

Conflict of interest The authors declare that they have no conflict of interest.

\section{References}

Anderson, M. (2007). Effect of integrated high-fidelity simulation on knowledge, perceived self-efficacy and satisfaction of nurse practitioner students in newborn assessment [doctoral thesis]. Texas Woman's University.

Barrows, H. S. (1993). An overview of the uses of standardized patients for teaching and evaluating clinical skills. Academic Medicine, 68(6), 443-451.

Barrows, H. S., \& Abrahamson, S. (1964). The programmed patient: A technique for appraising student performance in clinical neurology. Journal of Medical Education, 39(8), 802-805.

Beal, M. D., Kinnear, J., Anderson, C. R., Martin, T. D., Wamboldt, R., \& Hooper, L. (2017). The effectiveness of medical simulation in teaching medical students critical care medicine. Simulation in Healthcare: The Journal of the Society for Simulation in Healthcare, 12(2), 104-116. https://doi.org/10.1097/SIH.00000 00000000189.

Bogo, M., Katz, E., Regehr, C., Logie, C., Mylopoulos, M., \& Tufford, L. (2013). Toward understanding meta-competence: An analysis of students' reflection on their simulated interviews. Social Work Education, 32(2), 259-273.

Bogo, M., Rawlings, M., Katz, E., \& Logie, C. (2014). Using simulation in assessment and teaching. Council on Social Work Education.

Brown, T., Ewald, B., Gehlert, S., Bernstein, S. R., Andrews, C. M. Begin, A. L., Zabrack, B. J., Allen, H., Walther, V. N., Guth, S., Steketee, G., Ross, A., Maramaldi, P., Moore, M., Jones, B., Merighi, J. R., \& Golden, R. L. (2017). Strengthening health care systems: Better Health Across America. American Academy of Social Work and Social Welfare, Working Paper No. 22, Center for Inter Professional Education.

Bruce, L. (2013). Potential limitations of Dewey's perspective. Reflective Practice for Social Workers. Open University Press. pp. 36-40.

Cant, R. P., \& Cooper, J. C. (2010). Simulation-based learning in nurse education: Systematic review. Journal of Advanced Nursing, 66(1), 3-15. https://doi.org/10.1111/j.1365-2648.2009.05240.x.

Cantrell, M., Heard, J. K., Lindsey, M., \& Cleveland, E. (1997). Using standardized patients in the time-in/time-out interviewing technique. In A. J. Scherpbier, C. P. M. van der Vleuten, J. J. Rethans, \& A. F. W. van der Steeg (Eds.), Advances in medical education. Springer.

Close the Health Gap. GC Fact Sheet No. 2. (2018). https://grandchall engesforsocialwork.org/wp-content/uploads/2015/12/180604-GChealth-gap.pdf

Craig, S. (2016). Leveraging practice competence: Simulation learning $\&$ health social work. [PowerPoint Presentation]. Department of Social Work Services Grand Rounds, Mount Sinai Hospital, New York, NY.

Craig, S. L., McInroy, L. B., Bogo, M., \& Thompson, M. (2017). Enhancing competence in health social work education through simulation-based learning: Strategies from a case study of a family session. Journal of Social Work Education, 53, S47-S58. https:// doi.org/10.1080/10437797.2017.1288597.
Dunker, A. \& Benjamin, E. R. (2020). How structural inequalities in New York's health care system exacerbate health disparities during COVID-19 pandemic: A call for equitable reform. https://www.cssny.org/news/entry/structural-inequaliti es-in-new-yorks-health-care-system

Dunkin, B., Adrales, G. L., Apelgren, K., \& Mellinger, J. D. (2007). Surgical simulation: A current review. Surgical Endoscopy, 21(3), 357-366. https://doi.org/10.1007/s00464-006-9072-0.

Fowler-Durham, C. \& Alden, K. (2007). Enhancing patient safety in nursing education through patient simulation. In: Patient Safety and Quality: An Evidence-Based Handbook for Nurses, chapter 51 (Hughes R.G., ed.), US Department of Health and Human Services-Agency for Healthcare Research and Quality. http:// www.nhrq.gov/qual/nurses

Gaba, D. (2004). The future vision of simulation in health care. Quality Safety Health Care, 13(Suppl 1), i2-10. https://doi.org/ 10.1136/qhc.13.suppl_1.i2.

Gardner, R., Walzer, T. B., Simon, R., \& Raemer, D. B. (2008). Obstetric simulation as a risk control strategy: Course design and evaluation. Simulation in Healthcare, 3(2), 119-127. https://doi.org/10.1097/sih.0b013e3181671bbe.

Gavilanes, J.S., An, E. (2019). Types of healthcare simulation: locations and training-Who, what, and where? In: Crawford, S., Baily, L., Monks, S. (eds) Comprehensive healthcare simulation: Operations, technology, and innovative practice. Comprehensive Healthcare Simulation. Springer. https://doi.org/10. 1007/978-3-030-15378-6_2

Gligorov, N., Sommer, T. M., Ballato, E. C. T., Frank, L. E., \& Rhodes, R. (2015). Bridging the gap between knowledge and skill: Integrating standardized patients into bioethics education. Hastings Center Report, 45(5), 25-30. https://doi.org/10.1002/ hast.488.

Haluck, R. S., Satava, R. M., Fried, G., Lake, C., Ritter, E. M., Sachdeva, A. K., Seymour, N. E., Terry, M. L., \& Wilks, D. (2007). Establishing a simulation center for surgical skills: What to do and how to do it. Surgical Endoscopy, 21(7), 1223-1232. https://doi.org/10.1007/s00464-007-9689-7.

Hammond, J. (2004). Simulation in critical care and trauma education and training. Current Opinion in Critical Care, 10(5), 325-359. https://doi.org/10.1097/01.ccx.0000140950.47361.c9.

Hanberg, A. D. (2008). The diffusion of high fidelity simulation in nursing education: Barriers and recommendations for best practice. [Doctoral thesis, University of Northern Colorado]. Nursing \& Allied Health Database, ProQuest Dissertations Publishing.

Hegland, P. A., Aarlie, H., Strømme, H., \& Jamtvedt, G. (2017). Simulation-based training for nurses: Systematic review and metaanalysis. Nurse Education Today, 54, 6-20. https://doi.org/10. 1016/j.nedt.2017.04.004.

Henneman, E. A., \& Cunningham, H. (2005). Using clinical simulation to teach patient safety in an acute/critical care nursing course. Nurse Educator, 30(4), 172-177. https://doi.org/10.1097/00006 223-200507000-00010.

Hogg, G., Pirie, E. S., \& Ker, J. (2006). The use of simulated learning to promote safe blood transfusion practice. Nurse Education in Practice, 6(4), 214-223. https://doi.org/10.1016/j.nepr.2006.01. 004.

Hovancsek, M. (2007). Using simulation in nurse education. In Jeffires, P.R. (Ed.), Simulation in nursing education; from conceptualization to evaluation (pp. 1-9). National League for Nursing.

Issenberg, S. B., McGaghie, W. C., Petrusa, E. R., Gordon, D. L., \& Scalese, R. J. (2005). Features and uses of high-fidelity medical simulations that lead to effective learning: A BEME systematic review. Medical Teacher, 27(1), 10-28. https://doi.org/10.1080/ 01421590500046924.

Johnson, J., \& Panagioti, M. (2017). Interventions to improve the breaking of bad or difficult news by physicians, medical students, 
and interns/residents: A systematic review and meta-analysis. Academic Medicine, 93(9), 1400-1412. https://doi.org/10.1097/ ACM.0000000000002308.

Jones, F., Passos-Neto, C. E., \& Braghiroli, O. F. M. (2015). Simulation in medical education: Brief history and methodology. Principles and Practice of Clinical Research, 1(2), 53-62. https://doi.org/10. 21801/ppcrj.2015.12.8.

Kardong-Edgren, S. E., Starkweather, A. R., \& Ward, L. D. (2008). The integration of simulation into a clinical foundations of nursing course: Student and faculty perspectives. International Journal of Nursing Education Scholarship. https://doi.org/10.2202/1548923x.1603.

Kaufman, D. M. (2003). Applying educational theory in practice. British Medical Journal, J326(7382), 213-216. https://doi.org/ 10.1136/bmj.326.7382.213.

Kim, J., Park, J., \& Shin, S. (2016). Effectiveness of simulationbased nursing education depending on fidelity: a meta-analysis. BMC Medical Education, 16, 152. https://doi.org/10.1186/ s12909-016-0672-7.

Kneebone, R., Kidd, J., Nestel, D., Asvall, S., Paraskeva, P., \& Darzi, A. (2002). An innovative model for teaching and learning clinical procedures. Medical Education, 36, 628-634. https://doi.org/10. 1046/j.1365-2923.2002.01261.x.

Kneebone, R., Nestel, D., Wetzel, C., Black, S., Jacklin, R., Aggarwal, R., Yadollahi, F., Wolfe, J., Vincent, C., \& Darzi, A. (2006). The human face of simulation: Patient-focused simulation training. Academic Medicine, 81(10), 919-924.

Knowles, M. S. (1978). Andragogy: Adult learning theory in perspective. Adult and Student Learning: Special Collection, 5(3), 9-20. https://doi.org/10.1177/00915521780050030.

Kolb, D. (1984). Chapter 2: The process of experiential learning. Experiential learning: Experience as the source of learning and development. Prentice-Hall.

Kolb, D. \& Kolb, A. (2013). The Kolb Learning Style Inventory 4.0: Guide to Theory, Psychometrics, Research \& Applications.

Kourgiantakis, T., Sewell, K. M., Hu, R., Logan, J., \& Bogo, M. (2020). Simulation in social work education: A scoping review. Research on Social Work Practice, 30(4), 433-450.

Lasater, K. (2007). High-fidelity simulation and the development of clinical judgment: Students' experiences. The Journal of Nursing Education, 46(6), 269-276. https://doi.org/10.3928/01484 834-20070601-06.

Logie, C., Bogo, M., Regehr, C., \& Regehr, G. (2013). A critical appraisal of the use of standardized client simulations in social work education. Journal of Social Work Education, 49(1), 66-80. https://doi.org/10.1080/10437797.2013.755377.

Matthews, S. G., \& Phillips, D. I. W. (2010). Minireview: Transgenerational inheritance of the stress response: A new frontier in stress research. Endocrinology, 161(1), 7-13. https://doi.org/10.1210/ en.2009-0916.

McLaughlin, S., Fitch, M. T., Goval, G. G., Hayden, E., Kauh, C. Y., Laack, K., Nowicki, T., Okuda, Y., Palm, K., Pozner, C. N., Vozenilek, J., Wang, E., \& Gordon, J. A. (2008). Simulation in graduate medical education 2008: A review for Emergency Medicine.
Academic Emergency Medicine, 15(11), 11-17. https://doi.org/ 10.1111/j.1365-2648.2009.05240.x.

Murray, C., Grant, M. J., Howarth, M. L., \& Leigh, J. (2008). The use of simulation as a teaching and learning approach to support practice learning. Nurse Education in Practice, 8(1), 5-8. https:// doi.org/10.1016/j.nepr.2007.08.001.

Nackman, G. B., Bermann, M., \& Hammond, J. (2003). Effective use of human simulators in surgical education. Journal of Surgical Research, 115(2), 214-218. https://doi.org/10.1016/s00224804(03)00359-7.

National Association of Social Workers. (2017). NASW code of ethics. https://www.socialworkers.org/About/Ethics/Code-of-Ethics/ Code-of-Ethics

National Council of State Boards of Nursing. (2005). Clinical instruction in pre-licensure nursing programs. NCSBN.

Reilly, A., \& Spratt, C. (2007). The perceptions of undergraduate student nurses of high-fidelity simulation-based learning: A case report from the University of Tasmania. Nurse Education Today, 27(6), 542-550. https://doi.org/10.1016/j.nedt.2006.08.015.

Rosen, M. A., Hunt, E. A., Pronovost, P. J., Federowicz, M. A., \& Weaver, S. J. (2012). In situ simulation in continuing education for the health care professions: A systematic review. Journal of Continuing Education in the Health Professions, 32(4), 243-254. https://doi.org/10.1002/chp.21152.

Sandro, G. (2018). Healthier: Fifty thoughts on the foundations of population health. Oxford University Press.

Schön, D. A. (1983). The reflective practitioner: How professionals think in action. Basic Books.

Stanhope, V., Videka, L., Thorning, T., \& McKay, M. (2015). Moving towards integrated health: An opportunity for social work. Social Work in Health Care, 54, 383-407. https://doi.org/10.1080/00981 389.2015.1025122.

Sturm, L. P., Windsor, J. A., Cosman, P. H., Cregan, P., Hewett, P. J., \& Maddern, G. J. (2008). A systematic review of skills transfer after surgical simulation training. Annals of Surgery, 248(2), 166-179. https://doi.org/10.1097/sla.0b013e318176bf24.

Walters, K. L., Spencer, M. S., Smukler, M., Allen, H. L., Andrews, C., Browne, T., ... Uehara, E. (2016). Health equity: Eradicating health inequalities for future generations (Grand Challenges for Social Work Initiative Working Paper No. 19). Cleveland, OH: American Academy of Social Work and Social Welfare.

Publisher's Note Springer Nature remains neutral with regard to jurisdictional claims in published maps and institutional affiliations.

Emma D. Sollars LCSW, is the Program Coordinator for Training and Education in the Department of Social Work Services at The Mount Sinai Hospital.

Nancy Xenakis DSW, LCSW, MS is the Director, Department of Social Work Services at The Mount Sinai Hospital. 